\title{
Taking over someone else's design: implications for the tutor's role in networked learning
}

\author{
Mireia Asensio,* Janice Whatley** and Chris Jones* \\ *CSALT, Lancoster University, **Information Systems Institute, University of Salford \\ email:m.asensio@lancaster.ac.uk
}

The experience of taking over an already designed Web-based course helps us to investigate the claims in the literature about the role that tutors have more generally in networked learning. This paper addresses this issue through a case study and brings together the tutor's experience and her reflective diary, as well as the interview data from a JISC/CALT phenomenographic study of tutors' and students' experiences. This particular case study raises issues about the tutors' role, teaching activity, design and the value of content resources and knowledge representation. Finally the paper reflects on the implications for the tutor in this situation and provides suggestions for future practice.

\section{Introduction}

This paper reflects on the experiences of a particular tutor taking over a specific course. It is an example of a common situation found in higher education (HE) institutions, when newly appointed or temporary part-time or full-time staff are hired to teach courses that have been designed and developed by other members of teaching staff. The experience of this particular tutor may help us to illuminate the role that tutors have more generally in networked learning environments. For the purpose of clarification, we define networked learning as 'learning in which C\&IT is used to promote connections between one learner and other learners, between learners and tutors, between a learning community and its learning resources'.

A large part of this particular course was the focus on the connection between learners and the on-line Web learning resources, but there was also a significant element of interaction between learners and tutor and between the learners themselves, occurring on-line and via face-to-face events. In this paper we examine claims in the literature as to whether the tutor's 
role in a networked learning environment is qualitatively different from that in conventional teaching. The paper investigates some current literature in this area and specifically Collins and Berge's (1996) classification of tutor activity. Collins and Berge identify four main areas to which tutors in networked learning need to pay attention. These are pedagogical, social, managerial and technical teaching activities. Our research findings help us to explore those main areas, and the implications for the tutor's role when this involves taking over someone else's design of a mainly Web-based course. As a consequence other issues are raised on the value of content resources and knowledge representation.

Our research is based mainly on a phenomenographic approach to research (Marton, 1994; Marton and Booth, 1997) and utilizes both the tutor's experience and the use of a reflective diary. The study was carried out as part of a JISC/CALT Networked Learning Project in HE, UK. The tutor's diary detailed the tasks that arose, the reaction of the students to the module week by week, and the time spent by the tutor on amendments to the module. The diary was a 'vehicle for reflection' as suggested by Moon (1999), and was kept for the purpose of evaluating the module prior to redesigning it, as necessary, for the next academic year. This paper uses some edited extracts of the diary and includes a section on the tutor's experiences and suggestions for future practice. The JISC/CALT project has been looking at the students' and tutors' experiences across different uses of communication and information technologies for networked learning. The collaborative research between the tutor and the researchers of the JISC/CALT project has involved bringing together the tutor's diary and her general experiences about the course, and interviews with the original designer and the current tutor of the course.

\section{The tutor's role in networked learning}

This section examines the staff role in networked learning as it is portrayed in current literature. In broad outline, the role of the educator in networked learning environments has been summarized by the idea that the educator needs to move from 'the sage on the stage to the guide on the side'. The role of the tutor in a networked learning environment tends to be that of a facilitator or moderator. Early accounts of computer conferencing emphasized this shift (see, for example, Kerr, 1986; Feenberg, 1989). In more recent years the idea has become part of what has been described as a new paradigm of teaching and learning (Mason and Kaye, 1990; Harasim, Hiltz, Teles and Turoff, 1995; Koschmann, 1996; Reigeluth, 1999). The new role for the moderator/facilitator means that they 'must change from the purveyor of knowledge to instigator, promoter, coach, helper, model and guide of knowledge construction' (Jonassen, 1996: 261). Compared with other media, networked environments are said to emphasize social skills in teaching at the expense of content and personal delivery. Collins and Berge (1996), consolidating a wide range of literature, classify the tutor's role under four headings:

\section{Pedagogical (intellectual; task)}

Some of the most important roles of on-line discussion instructor/moderator/tutor revolve around their duties as an educational facilitator. The instructor contributes their special knowledge and insights and uses questions and probes for student responses that focus discussions on critical concepts, principles and skills. By modelling appropriate on-line behaviour, the instructor can prepare students, alone or in groups, to experience moderating the conference for themselves. 


\section{Social}

Creating a friendly, social environment in which learning is promoted is also essential for successful on-line teaching. This suggests promoting human relationships (affirming and rccognizing students' input, providing opportunities for students to develop a sense of group cohesiveness, maintaining the group as a unit, and in other ways helping members to work together in a mutual cause) are all critical to the success of any conferencing activities.

\section{Managerial (organizational; procedural; administrative)}

This role involves setting the agenda and pacing for the conference: the objectives of the discussion, the timetable, procedural rules and decision-making norms. Meta-comments can be used to remedy problems in context, norms or agenda, clarity or irrelevance, and help participants deal with information overload. Unobtrusively managing the flow and direction of the conference discussion without stifling the participants is a sine qua non of successful conference facilitation.

\section{Technical}

The instructor must first become comfortable and proficient with the technology, and then must ensure that participants are comfortable with the system and the software that the conference is using. The ultimate technical goal for the instructor is to make the technology transparent. When this is done, the learner may concentrate on the academic task at hand.

\section{Introduction to the case study}

The case study was a third-year course entitled 'Developing Systems for Teaching and Learning' taught in the Information Systems Institute (ISI) at the University of Salford. This module was concerned with exploring the development of information systems for teaching and learning, and it aimed to provide the theoretical underpinning and practical experiences needed for the development of education and training systems. The original designers of the course have written a report (Nicholson and Bird, 1998), which outlines reasons for adopting their particular approach to Web-based teaching and learning to the course design. They described the course as an answer to growing student numbers. It was also designed to cope with a changing student population, involving increasing numbers of non-traditional students (Nicholson and Bird, 1998). The Web site was intended to provide the main medium for teaching and learning, and the face-to-face lectures and seminars were intended to supplement or complement the main Web-based material.

Prior to the case study being undertaken, but after access had been agreed for the researchers to interview the students, both members of staff responsible for the course obtained jobs elsewhere. The new member of staff, who had been appointed on a temporary full-time contract, agreed to allow the JISC/CALT study to continue. This case study has, as a consequence of this change, the added dimension of being taught by a lecturer not responsible for the initial design. The new tutor was also new to the centre and the course subject; she had access to the on-line material, some other course resources and some of the journal papers written by the previous tutors. However she did not have the opportunity to talk to these tutors about the course and the design itself, or about their reflections on any problems encountered throughout the course. She had limited support 
and little time to become familiar with the Web site, resources, aims, objectives and assessment procedures for the course.

The module comprised Web-based material covering educational theory and design principles. The Web site contained a freeware conferencing utility, the course administration, syllabus and assignment details, learning resources exercises and virtual spaces for the students to interact with each other and the tutor. There was a space for informal chat and a virtual seminar to discuss the course content. The virtual seminar was structured around the course into themes and one seminar space was set up for teams to give feedback to each other about their project work. The Web site also contained an archive allowing students to look at previous years' design projects.

The course had a team work component that was informed by ideas about co-operative learning. The students' experiences of this were marked by the general context of the degree structure, as the entire degree was built around teamwork. The students had broad experience of working in this way within ISI and also occasionally undertook 'commissions' for outside bodies, in teams composed of first-, second- and third-year students. Thus the students on this third-year course were very experienced in team working, in a variety of settings with a number of different team members.

The assessment consisted of five different components; an individual element comprised 20 per cent and a teamwork element comprised 80 per cent of the final mark. The project was the major component of the course assessment, in which student teams of five were expected to build a prototype for a Web site on a topic of their choice, as a learning and instructional system. Project titles included topics such as astrology for beginners, the basics of guitar-playing, how to upgrade and maintain a PC, etc. Each team was expected to describe the design, purpose and intention of their Web site and to provide feedback to the other teams on their project proposals. The marking scheme contained an element of self and peer assessment. Within teams, individuals were peer-assessed by the members of their own team. Team projects were assessed anonymously by the other teams and the tutor collated these marks, which were used to moderate the final marks determined by the tutor.

\section{Implications for the networked learning tutor}

In the context of this particular course and situation we explore how Collins and Berge's (1996) classification of the different activities that a tutor should take into account, that is, pedagogical, social, managerial and technical, apply to this tutor's experience.

\section{Managerial and technical issues}

When the tutor described her experience her main focus was on the managerial and technical issues that she had to deal with before the course started. She commented that, in the same way that developing an on-line course requires considerable input 'up front', updating an existing course also requires a great deal of input before the course is used. Compared with a lecture-based course, she did not have to write or adapt lecture material, but needed to familiarize herself with the published content material. The following text is an edited version of the tutor's thoughts and reflections from her diary:

The structure of the course in terms of assessment dates and progress through the material needed to be sorted before going live. Unlike a lecture-based course there is no 
option to sort out dates and material as the course progressed. This took sixteen hours before it started plus the reading to familiarize myself with the course material. This was quite time-consuming as I read it on-line as the students will need to. At the beginning I assumed that I would be able to read up again on each section just before the students were programmed to get there. The 35 hours were. on top of the 2 hours allocated each week for lectures, tutorials or seeing students about their work. This time probably represents about the same time as would be spent on a traditional lecture-based course, so there was little saving through the module being on-line.

A crucial element we have identified, as indicated below in the tutor's quotation from the interview, is the fact that time pressure was a main constraint to redesigning the course content before the course started. This means that the tutor had to take the course content at face value, and try to amend/change it throughout the course.

So as well as doing two full modules I was then going to do six weeks of this which brought me right up to Easter so the time pressure got worse actually, I wasn't able to look at the site, spend any time on it basically, I was fire-fighting from then on.

If we think of taking over a conventional teaching course, we find that the tutor has more flexibility to change the content of the course before each class: the tutor can prepare a new set of slides the night before if they wish to do so. In a Web-based course, in which all the learning resources are available to the students from day one, the tutor lacks flexibility. In the case described here, she had no time to make any major changes to the course content and design, apart from updating the sections on course administration. She took the pedagogical design at face value and hoped to be able to redesign it as the course progressed over the weeks. Interestingly the tutor had also taken over a conventional lecturing course on Systems Design, a comparison with which shed light on the differences in tutor role in this medium. As the tutor said during the interview:

Um it's probably easier to pick up a load of acetates and be able to deliver a fifty-minute lecture than it is to read through Web materials and think of some tutorial sessions that you should prepare with them ... by contrast we have here something that all the course materials were there at the beginning. Actually yes, the big difference is that I prepared material as I went along for the hour lectures, so at the beginning I'd only done three weeks' lecture notes, then I sort of carried on and I was preparing stuff as I went along ... it was easier because nothing was set in stone from the beginning.

The 'set in stone' analogy is revealing, as it points out that taking over the networked learning course implied taking over, at least temporarily, the previous tutors' representation of knowledge and their personal understanding of the students' intended learning experience. Interestingly as the course progressed the tutor became more aware of how the material had been presented and she perceived mismatches between aims, objectives and assessment. This was also exacerbated by the lack of course design documentation and specification up front. In addition she saw herself having to understand and internalize the content at the same time.

Not having done the course or known what it was all about before, I was actually trying to read the material on-line at the same time as trying to update things ... But there was 
no material there that directed you to what was on the site; I had to map it out myself and that's one criticism of the site that I don't think it's very clearly mapped and the students have said that when they've done the personal reflection at the end of the course, they thought in cases it was very messy and they didn't know where they were. So that's one thing that needs altering. (tutor's interview)

This indicates that because in a Web-based course the content is 'set in stone', the on-line tutor has less flexibility, at least at the beginning, to readapt the Web site. Moreover, as the tutor was trying to make sense herself of how the course content had been presented, given the time constraints and other work pressures, this also caused some anxiety. She described the whole experience as feeling like 'fire-fighting from then on' once the courses started, trying to catch up particularly with the redesign of the networked learning course. This emphasizes the importance of well-structured Web pages and smooth navigation to aid both the tutor and the students.

As a teacher I felt that I was perhaps letting the students down a little bit in that I wasn't always able to get back to them immediately with an answer to a question, assignments took me a little bit longer to mark because I was trying to figure out how to mark them, so I do feel I let the students down a little bit in a way, but at the end of the day most of them appreciated that $I$ was under pressure and taking the course on face value they actually enjoyed what they did in the course, so that negated any criticism of my management of it. So in the end it wasn't too bad but I feel I could have done it a lot better given a little bit more time. (tutor's interview)

This experience seems to indicate that because of time pressure, the tutor could only pay attention to two immediate priorities: the managerial and the technical. This is not to say that she did not consider, think or care about the pedagogical and social implications of the course.

\section{Pedagogical and social issues: the importance of face-to-face tutorials}

The tutor found that regular face-to-face tutorials could compensate for the lack of time that she had to amend the site and resource material, in a way that would better represent her educational view of the course and teaching style.

The only way I could alter anything is to actually put in a tutorial, actually prepare some material that filled in the gaps and present it at a tutorial session/face-to-face session as an extra which I did . . . in terms of the degree qualification you are trying to get the students to think about things, compare, contrast and delve a little deeper into some of the things, whereas the material on-line is a very superficial look at theory. You either take it that it's there so it must be fact, a bit like reading it from a book ... so the face-to-face tutorial is the only opportunity to actually discuss any of those 'now do you think it is right or are there not occasions where this theory might be slightly wrong?' (tutor's interview)

This raises the issue that the course content and delivery style was very personal and unique to the previous tutor. In other words the Web site and the choice of content represents the tutor's design and representation of knowledge and, arguably, not that of the student. Conversely we could suggest that in a text-based computer conferencing environment, the opportunities for sharing and building on the students' as well as the 
tutor's previous experiences and knowledge, do not as clearly overemphasize the tutor's view of the world and representation of knowledge. It appears that in this type of course the role of the tutor is also perceived by the students to be that of the 'subject expert'. Not surprisingly the new tutor found herself in a situation of both trying to comprehend someone else's design rationale and become acquainted with the course content. It appears to us that the face-to-face tutorials provided the means to bridge the gap of mutual understanding between the interpretation of the tutor of the course content and that of the students. However it is worth noting that a truly on-line module would pose difficulties in this respect. The ability to generate reflection from students is an important part of learning, which as Salmon (2000) notes is a different tutor role on-line from that for a faceto-face environment. A virtual seminar potentially enables this sort of discussion, but it requires tutorial facilitation to elicit meaningful reflection.

A true on-line course would of course have no tutorials, and some students were happy with this arrangement, whereas others liked to have a regular weekly contact time. 'It would be wrong to present material which those who did not want to come would miss out on, as attendance was not stipulated on this module, except for certain sessions' (tutor's diary).

Indeed the difficulty was to offer equal access to content material and information on the course to all the students, given that on-line provision might offer a choice for students. However, the majority of students attended the tutorials, though these were not explicitly compulsory. Hence our interpretation that the face-to-face tutorials provided the means to check understanding with the students. They were a way of making sense of the content and the course objectives. We can argue that they also provided an opportunity for the students to socialize as a class, to see each other and discuss issues as a whole group. This could have provided the way to include the pedagogical and the social activities. The use of the virtual seminar was so patchy that the tutor found it difficult to check understanding from the postings made. The questions posed to the virtual seminar needed to have clear objectives for them to form the basis of a useful discussion. In addition, both the face-toface tutorials and the fact that students saw each other regularly for their project work meetings hindered the students' active participation in the virtual seminar.

\section{Tutor's experience and suggestions for future practice}

In detailing such an account of progress regularly using a reflective diary it is possible to have a more objective view of the module. It was possible to identify patterns in the need to perform some tasks and to list these tasks in the form of a checklist for completion the next time the module is run. The diary also proved invaluable for comparing the work involved in running this on-line module with that involved in running a traditional lecture-based module.

The problems encountered whilst updating the module were:

- learning the Web development tool Dreamweaver;

- understanding the rationale for the assessments and the marking schemes;

- finding the individual Web pages for alteration; 
- planning appropriate topics for tutorials.

The tasks that needed completing before the module commenced included:

- altering all references to dates for lectures and tutorials;

- changing module leader contact details;

- clearing out the previous cohort's virtual conference contributions;

- moving the previous cohort's team work to an archive;

- becoming familiar with the learning material.

The technical difficulties meant that the tutor was unable to devote as much attention to the pedagogical and social areas of the module. It was found that more than sixteen hours were devoted to making technical alterations before the module started, followed by over thirty-five hours as the module was running. These times were in addition to the allotted tutorial times each week. Ideally the module should be technically complete prior to commencement to enable the tutor to concentrate on pedagogical and social issues as the module is running.

As a result of the tutor's experiences a list of suggestions for designing online courses is presented:

- keep timetable elements in a limited number of pages, which are documented;

- ensure there is good documentation with answers to exercises and MCQs (multiple choice questions);

- there should be a clear map or outline with navigation between pages;

- ensure discussion topics have clear objectives;

- be rigorous when defining assignment specifications with marking schemes.

\section{Discussion and conclusion}

If we think of the implications for the tutor's role in this situation, it is important to be aware of time pressure and lack of course design documentation and specification, and how this may affect the order of the priorities that we need to pay attention to. In this particular case the order of activities that the tutor had to take into account - given the time pressures - clearly prioritized the technical and managerial side over the pedagogical and social responsibilities, which, according to Collins and Berge's (1996) classification of tutor activity, should be the first two priorities in the networked learning environment.

It appears that the literature on the tutor's role and activities in a networked learning environment refer more widely to CMC (computer-mediated communication). However, when addressing a Web resource-based course, we have found that other implications for the tutor arise. The study we have made of a Web-based course might suggest that the role of the tutor is not only that of the moderator/facilitator/guide, but also that of the subject expert. This is clearly reflected on the content materials and resources developed by the tutor and in turn in the overall design of the course. 
This case study illustrates that design encapsulates an individual or individuals' view of knowledge and understanding of the students' learning experience. We have explored elsewhere the practitioners' accounts of design in networked learning and how the design process and outcome is informed by assumptions about the nature of learning and the learning process (Jones and Asensio, 2001). This case study brings about an added understanding of design itself. Taking over someone else's design implies taking over someone else's representation of knowledge: this is exemplified here by the tutor's experience of having to familiarize herself with the course design and content.

In this situation it also appears that the face-to-face tutorials were a way to embed pedagogy and social interaction. Interestingly, the students in the course did not report that they had been directly affected by the tutor being new to the course and found the tutorials useful. This supports the belief that the value did not lie in the content alone, but in how it was managed by the tutor and used by the students. This raises the issue of whether the added value of the course is not the stated content in itself (which is only a partial and personal representation) but the input of the teacher who is taking over the course, and the students' approach to the course material. Clearly face-to-face tutorials are not always possible in the networked learning environment and the increasing demand to provide flexible and open access to a global student market may hinder face-to-face contact. The danger is that increasing numbers of tutors in HE may be in a similar situation in the future, and that time constraints may adversely affect the more pedagogical and social aspects of the teaching activity.

\section{Acknowledgement}

This work was part-funded by a grant from the Committee on Awareness, Liaison and Training of JISC (the Joint Information Systems Committee of the UK higher education funding councils). The views expressed here are not necessarily those of JISC CALT. Further information about the project can be obtained from the project's Web site (http://csalt.lancs.acuk/jiscl). We would like to thank the previous tutor in the course and all those students that took part in the interviews. We would like to acknowledge the contributions of other members of the project team: Peter Goodyear, Vivien Hodgson, Christine Steeples, Susan Armitage, Mark Bryson, Michael O'Donoghue and David Hutchison. Finally we would like to thank the two anonymous reviewers and Clive Young for their helpful comments.

\section{References}

Collins, M. and Berge, Z. (1996), 'Facilitating interaction in computer mediated on-line courses', on-line at http://emoderators. com/moderators/flcc.html.

Feenberg, A. (1989), 'The written world: on the theory and practice of computer conferencing', in R. Mason, R. Kaye and A. Kaye (eds), Mindweave: Communications, Computers and Distance Education, Oxford: Pergamon Press. Out of print but available online at $h t t p: / / w w w-i c d l . o p e n . a c . u k / m i n d w e a v e l m i n d w e a v e . h t m l$.

Harasim, L., Hiltz, S. R., Teles, L. and Turoff, M. (1995), Learning Networks: A Field Guide to Teaching and Learning Online, Cambridge, MA.: MIT Press. 
Jonassen, D. H. (1996), Computers in the Classroom: Mindtools for Critical Thinking, Englewood Cliffs, NJ: Merrill, Prentice Hall.

Jones, C. and Asensio, M (forthcoming, 2001), 'Designs for networked learning: a phenomenographic investigation of practitioners' accounts of design', to be published in an edited collection, Springer Verlag.

Kerr, E. (1986), 'Electronic leadership: a guide to moderating on-line conferences', IEEE Transactions on Professional Communications, PC, 29 (1), 12-18.

Koschmann, T. (ed.) (1996), CSCL: Theory and Practice of an Emerging Paradigm, Mahwah, NJ: Lawrence Erlbaum Associates.

Marton, F. (1994). 'Phenomenography', in T. Husen and T. N. Postlethwaite (eds), The International Encyclopedia of Education (2nd edn), Oxford: Pergamon, 4424-9.

Marton, F., and Booth, S. (1997), Learning and Awareness, Mahwah, NJ: Lawrence Erlbaum Associates.

Mason, R. and Kaye, A. (1990), 'Towards a new paradigm for distance education', in L. Harasim (ed.), Online Education: Perspectives on a New Environment, New York: Praeger.

Moon, J. (1999), Learning Journals Handbook for Academics, Students and Professional Development, London: Kogan Page.

Nicholson, B. and Bird, D. (1998), 'Using the World Wide Web and computer conferencing to improve campus based teaching and learning', http://salford.acuk/itilpapers/ m320eval.htm [last accessed 5 July 2000].

Reigeluth, C. (ed.) (1999), Instructional-Design Theories and Models Volume II. A New Paradigm of Instructional Design, London: LEA.

Salmon, G. (2000), E-moderating: The Key to Teaching and Learning Online, London: Kogan Page. 